\title{
Francesco de Martino y Carmen Morenilla (Eds.) Teatro y Sociedad en la Antigüedad Clásica. Personajes secundarios con historia. Serie "Le Rane" STUDI - 63, Levante editori, Bari, 2016, 533 pp.
}

\author{
María Inés Moretti *
}

* Universidad Nacional de La Plata, Argentina

Francesco De Martino y Carmen Morenilla Talens nos ofrecen un nuevo volumen colectivo, resultado del decimonoveno Congreso Internacional de Teatro Grecolatino y su Pervivencia en la Cultura Occidental, el último de la serie de encuentros que viene organizando anualmente, desde 1997, el GRATUV (Group de Recerca i Acció Teatral de la Universitat de València). En esta ocasión, y en continuidad con las investigaciones que el grupo lleva a cabo desde el año 2013, los trabajos se centran en el proceso de creación de un personaje secundario a partir del bagaje que ofrece la tradición.

En las "Palabras preliminares", los editores destacan la importancia de los personajes secundarios, partiendo de la idea de que no siempre resultan tan subsidiarios como podría parecer. Ellos señalan que las investigaciones que el libro reúne parten de la hipótesis de que la pericia del dramaturgo puede llegar a crear personajes secundarios muy particulares con papeles relevantes, algunos, incluso, decisivos en las tramas. A través de la observación de la figura del personaje secundario, la posición que realmente ocupa en la acción dramática, su interacción con los restantes personajes y su grado de adscripción o no a una figura dramática con características relativamente fijas, los diversos estudios ayudan a desentrañar la tensión entre los datos procedentes de la tradición de la que surge la obra y en la que se inserta y el espíritu transformador con que el dramaturgo se sirve de ellos en obras clásicas y de recepción de teatro clásico.

Como en los volúmenes previos de la misma colección, este número se divide en dos partes: “Teatro grecolatino" y "La recepción del teatro greco-latino".

Nueve trabajos componen la primera parte del libro. Dos de ellos centran su interés en personajes heroicos que no han ocupado lugares protagónicos en el drama ateniense. F. Javier Campos Daroca, en “El cuerpo de 
Euristeo en Heraclidas. Exploraciones trágicas del culto heroico", se propone reevaluar la función de Euristeo en Heraclidas, de Eurípides, analizando el modo en que el personaje se hace presente en el curso de la pieza desde fuera de la escena y las figuras políticas y religiosas elaboradas por su mediación. Por su parte, Lucía P. Romero Mariscal, en su artículo "Deífobo en Alejandro de Eurípides: un personaje secundario con historia”, estudia el modo en que el héroe troyano se inserta en la trama del conflicto familiar que está en el centro de esta tragedia perdida de Eurípides, como personaje secundario pero especialmente eficaz, tanto para hacer avanzar el argumento como para vehicular la caracterización de los personajes del drama.

Resulta interesante el abordaje de personajes divinos. En ese sentido, el artículo de Francesco De Martino, “Charon ille. Storia di un personaggio secondario", estudia el personaje de Caronte en Ranas de Aristófanes y en otras fuentes, a través de un exhaustivo rastreo de sus apariciones en la literatura griega y latina. Por su parte, Juan Luis López Cruces, en "Cástor y Polideuces, secundarios dramáticos”, se ocupa de las raras apariciones de los Dióscuros en el teatro griego y observa de qué modo reciben caracterizaciones independientes como héroes mortales pero pierden sus rasgos específicos y actúan de forma conjunta como divinidades.

Jaume Pòrtulas aborda una clase especial de personajes secundarios en la tragedia griega: las estatuas y los simulacros. "La nostalgia del doppio" estudia este tipo de personajes en Agamenón, de Esquilo, y en el teatro de Eurípides, en particular en Alcestes y en la tragedia perdida Protesilao.

Sobre mujeres griegas en calidad de personajes secundarios, escriben Maria do Céu Fialho, con “Clitemnestra en Áulide: el inicio de una larga historia”, y Mariateresa Galaz, con "Hermíone o el paso de

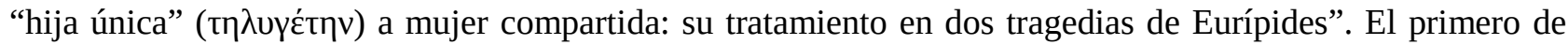
los artículos se refiere a la caracterización de Clitemnestra como madre amorosa y esposa devota y el modo en que, junto con su hija, funciona como contraste con respecto a los hombres de guerra y sus maniobras engañosas. El segundo artículo se centra en el personaje de Hermíone en Andrómaca y Orestes, y analiza como una reinterpretación del mito esta ruta de personaje co-protagónico a personaje secundario que Eurípides elige para ella.

Los dos últimos estudios de la sección toman como eje a criados, heraldos y otros personajes secundarios anónimos. "Criados fieles en casa de Agamenón: el centinela (Esquilo, Agamenón) y el viejo (Eurípides, Ifigenia en Áulide)”, de María de Fátima Silva, se concentra en las figuras menores del drama ático que atrajeron la atención de los dramaturgos y adquirieron personalidades y perfiles definidos, al tiempo que contribuyeron, por contraste, al diseño de los héroes y protagonistas. El artículo explora ciertos vínculos entre el centinela de Agamenón de Esquilo y el servidor de Ifigenia en Áulide de Eurípides. Por su parte, "Personaggi minori nel dramma attico. Considerazioni sulla loro caratterizzazione e funzione drammatica in Sofocle”, de Bernhard Zimmermann, explora la función de los personajes de la tragedia sofoclea que, en contraste con los héroes, han recibido una menor atención de los estudiosos: los heraldos y otros personajes menores anónimos.

La segunda parte del libro está dedicada a la recepción del teatro greco-latino en diferentes épocas y contextos culturales. El primer artículo de la sección, de Corrado Cuccoro, "Ruoli attanziali e valenze simboliche della Sfinge nella drammaturgia edipica, dall'epoca del simbolismo ai giorni nostri”, presenta un estudio de las fuentes antiguas sobre la Esfinge para centrarse luego en diecinueve versiones modernas de esta figura del mito de Edipo. El autor ofrece, finalmente, a modo de apéndice, una antología.

Las nodrizas ocupan un lugar privilegiado en esta sección. En primer lugar, Charles Delattre, en "Nourrices conspiratrices: des nourrices sans histoire?”, estudia la presencia de nodrizas en el corpus mitográfico del período imperial y observa de qué modo se desarrolla el estatus de estos personajes, secundarios en el teatro 
greco-latino, y cómo en este período se incrementa su participación en las obras. Por su parte, "De la sumisión a la pasión. De Oenone, en la Phedre de Racine a mrs. Danvers en Rebecca, de Daphne du Maurier-Hitchcock”, de Juli Leal, explora la presencia de la nodriza de Fedra a partir de la reelaboración del personaje de Eurípides y de Racine, especialmente en la novela Rebecca de Daphne du Maurier y en el film de Hitchcock que lleva el mismo nombre. A su vez, Aurora López y Andrés Pociña también se concentran en este personaje, tomando un corpus diferente. “La nodriza de Fedra desde Hipólito de Eurípides a Phaedras's Love de Sarah Kane” realiza un rastreo de este personaje en Hipólito de Eurípides y en Fedra de Séneca, con sus distintos significados, y procede luego a analizar las nodrizas de Fedra de Racine, Fedra de Gabriele D’Annunzio, Fedra de Miguel de Unamuno, Fedra de Lourdes Ortiz y el personaje Estrofa en Phaedras's Love de Sarah Kane. Ellos llegan a la conclusión de que la reescritura muestra que la nodriza se ha vuelto una figura inevitable, a pesar de ser un personaje secundario.

Diversos estudios abordan la conversión de ciertos personajes del drama ático de secundarios a protagónicos. Salvatore Francesco Lattarulo, en "«Ma, chi era Pilade?»: variazioni pasoliniane su un eroe secondario del mito” observa de qué modo Pasolini usa un personaje secundario de la Orestíada y lo desarrolla para sus propios propósitos tomando elementos de las escenas de Eurípides en las que aparece. El artículo de Carlos Morais, "Salida de la sombra: la Ismena de Agustín García Calvo”, estudia la transformación en heroína del personaje de Ismena, personaje muchas veces ausente o a la sombra de Antígona en las diversas reelaboraciones del mito. Morais examina la Ismena del dramaturgo español y cómo ella se erige en defensora de los intereses de su gente. Por su parte, "Ferete, padre di Admeto. Storia di un personaggio, da secondario a comprimario, nelle riscritture dell'Alcesti di Euripide”, de Maria Pia Pattoni, rastrea las reescrituras del personaje de Feres y la manera en la que ha variado el tratamiento del conflicto padre-hijo, a partir de juicios de valor diferentes, en la recepción del mito en los siglos XVIII, XIX y XX.

David García Pérez, en "La conversión de Minotauro: de antihéroe a redentor”, estudia el cambio de valoración de este personaje en "La casa de Asterión”, de J. L. Borges y Los Reyes, de J. Cortázar, que ocurre cuando el minotauro es aislado del sistema de relaciones antagónicas que se establece en la tragedia.

La ópera y el burlesco tienen lugar en dos interesantes estudios. "Amor, ironía y simulacro: la isla de Alcina”, de Enrique Gavilán, interpreta a través de los paralelismos con la Circe homérica al personaje de Alcina, la hechicera creada por Ariosto y retomada luego en la ópera de Händel. Por su parte, Laura MonrósGaspar, en "Minerva bas-bleu: personajes secundarios con una historia social en Prometheus unbound; or, the man on the rock (1865) de Robert Reece", estudia cómo el personaje de Minerva en la pieza de Robet Reece, con el sincretismo anacrónico que es distintivo del teatro burlesco victoriano, manifiesta los debates de género de mediados del siglo XIX en torno a las mujeres y la educación y anticipa, a su vez, la representación peyorativa de las mujeres intelectuales que prevalece en el último período del siglo XIX.

Cierra este volumen un “Apéndice” con los resúmenes del II Foro Gratuv de Jóvenes Investigadores, un espacio diferenciado para investigadores en formación, inaugurado en el decimoctavo Congreso del Grup de Recerca i Acció Teatral que, como señalan los editores en las "Palabras preliminares", da muestra de una firme y resuelta vocación de continuidad.

Un índice de nombres antiguos, presente al final del libro, facilita significativamente la búsqueda singular dentro del rico conjunto de estudios. 
Como todas las obras que presenta cada año el Grup de Recerca i Acció Teatral, este nuevo volumen constituye una muestra de rigor científico y profundidad investigativa, en los que se deja ver también el empeño y la labor de los editores, en la criteriosa selección de los temas y autores. Sin duda una obra de consulta enriquecedora para los estudiosos del mundo antiguo y los interesados en el teatro clásico y su recepción. 